\title{
Research on the Strategy of Humanistic Cooperation Between Jilin Province and the Russian Far East*
}

\author{
Chunyi Liu \\ Northeast Electric Power University \\ Jilin, China 132012
}

\begin{abstract}
At present, the cooperation between Jilin province and the Russian Far East in the field of humanities has achieved remarkable success. The scope of cooperation is gradually widening, and the form of cooperation is also characterized by socialization, hierarchical and diversification. However, the depth and breadth of cooperation remain to be promoted, and the social potential of cooperation needs to be stimulated by the normal state. We should constantly improve and perfect the bilateral humanistic cooperation strategies from the government, social, market and organizational levels.
\end{abstract}

Keywords-Jilin Province; Russian Far East; humanistic cooperation; strategy

\section{INTRODUCTION}

The report of the 18th CPC National Congress has clearly put forward the view of promoting humanistic exchanges and cooperation with foreign countries. The Sino-Russia Joint Declaration in 2012 had pointed out that the two countries should expand and deepen the cooperation in the field of humanities in an all-round way in order to consolidate the social foundation of the strategic partnership of cooperation between China and Russia.

\section{The CONNOTATION AND MEANING OF HUMANISTIC COOPERATION}

The term "humanity" refers to human civilization. All the cultural achievements created by mankind and the practical activities that human beings engage in belong to "humanity". "Humanity" first appeared in the historical document "Zhouyi - Divinatory Symbols of Bi", "Men are rigid and women are soft, a man and a woman forms a family, this is natural; a country, the world, is humanity. By this we can observe the law of the operation of the heavens, to realize the changes of the season; pay attention to ethics and use it for education and promote it in the world"[1]. "Humanity" here refers to social human relation. In the dictionary "Collection of Words", "humanity refers to various cultural phenomena of human society". However, in western countries, "humanity" is defined as "the subject and general knowledge of exploring human emotion, morality and sense with observation, analysis and criticism, such as philosophy, literature, art, history and

*Project Funds: Funds for Philosophy and Social Science of Jilin Province "Research on the Strategy of Humanistic Cooperation between Jilin Province and the Russian Far East under the Framework of Changchun-JilinTumen Development Strategy", Project number: 2014B222. language, etc."[2] Therefore, "humanity" in contemporary society covers the fields of culture, art, education, health, sports, law, tourism, and society, etc ${ }^{1}$. While "cooperation" refers to a joint action and mode between people and groups in order to achieve common purposes. "Humanistic cooperation" can be interpreted as "the interaction, communication and joint action of people in the fields of culture, art, education, health, sports, law, tourism, and society to achieve common purposes."

As a kind of spiritual power, culture can be transformed into material power in the process of people's understanding and transformation of the world. It has a profound influence on the development of society and human beings. Strengthening humanistic cooperation with Russia is conducive to promote social development in both countries. Russian President Putin pointed out that only on the basis of cultural exchanges and cooperation that China and Russia can build the most important cornerstone of bilateral relations - mutual trust. Without this foundation, it is impossible to talk about cooperation in other fields. Mina Gil, a famous Russian scholar, said when evaluating Sino-Russia cooperation, "now there is nothing between the two countries except doing business. You know, the relationship between the two countries is fragile without humanistic exchanges and peopleto-people communication."[3] Therefore, humanistic cooperation has become the third driving force behind the development of relations between two countries after political and security cooperation and economic and trade cooperation, which is more profound than the political exchange, and is deeper than the economic and trade exchanges. It has the characteristics of basic, pilot, extensive and persistent.[4] At present, the humanistic cooperation between the two countries has covered nine fields including education, culture, health, sports, tourism, media, film, archives and youth. In 2014, China and Russia "Year of Youth" provided a historic opportunity to further deepen the cooperation between the two sides.

Jilin is located in the central part of Northeast China, and has a common border with Russia Far East ${ }^{2}$ in the east. It has

The contents of "humanity" cover the scope of: art, film, music, mythology, dance and opera in the field of art; learning, science and quality in the field of education; and religion and thought in the field of philosophy, etc.

"Russian Far East" refers to the region of Russia on the verge of the Pacific Ocean. It consists of 9 administrative regions, namely, Amur, Jewish Autonomous Oblast, Kamchatka Kray, Magadan, Maritime Kray, 
the advantages of close geopolitical relationship and affinity in implementing Sino-Russia cooperation. In recent years, the Russian government has paid more and more attention to the construction of the Far East, and has approved a series of important plans and strategies for its development ${ }^{3}$, which have effectively promoted the cooperation and development of the Far East and Northeast China. At the same time, the implementation of "Changchun-Jilin-Tumen Development Strategy" has provided a broad platform for the development of Jilin's cooperation with Russia. The main content of this paper is to explore the methods of how to use this platform to make the humanistic exchanges and cooperation between to two sides more active and thus to promote the cooperation between the two countries.

\section{The CURRENT SITUATION OF HUMANISTIC COOPERATION BETWEEN JILIN PROVINCE AND THE RUSSIAN FAR EAST}

Strengthening bilateral cultural cooperation is conducive to the appreciation, tolerance and recognition of the two peoples' cultures and civilizations, so that they can learn from each other and merge with each other. At the present stage, the scope of humanistic cooperation between Jilin and the Russian Far East is gradually widening. The form of cooperation is also characterized by socialization, hierarchical and diversification, and the cooperative development is carried out orderly. However, the depth and breadth of cooperation remain to be promoted, and the social potential of cooperation needs to be stimulated by the normal state. We should constantly improve and perfect the bilateral humanistic cooperation strategies from the government, social, market and organizational levels.

\section{A. Remarkable Achievements of Humanistic Cooperation Between Jilin Province and the Russian Far East}

Under the background of "Changchun-Jilin-Tumen Development Strategy", the two sides have carried out various forms of exchanges and cooperation in the fields of culture, education, tourism, art and science and technology, and have made some remarkable achievements.

In September 2011, Jilin Province carried out Jilin Cultural Week in Russia. The song and dance performance "Charm of Changbai" reached several climax; "Colorful Jilin" photography exhibition was warmly welcomed; the cultural industry promotion was pursued by the public; folk arts and crafts such as songhua inkstone, paper cutting, knife painting, micro carving and farmer painting are displayed, which fully displayed the folk arts and crafts and intangible cultural heritage of Jilin, being loved by the Russian people.

Saha Republic, Sakhalinskaya Oblast, Khabarovskiy Kray and Chukchi Autonomous Okrug, with a total area of 6,214,673 square kilometers, accounts for $36.4 \%$ of the country's total area. The population is 7.02 million, accounts for $4.9 \%$ of the total population. The capital of the federal district is Khabarovsk.

The development plan and strategy of the Far East mainly include "Outline of Cooperation Planning between Northeast China and Russian Far East and East Siberia region (2009-2018)" which was jointly approved by the heads China and Russia in 2009, and "Social and Economic Development Strategy for Far East and Baykal Region before 2025", which was formulated by the Russian government in 2010 .
In June 2012, Changchun of Jilin Province held a "SinoRussia Tourism Week" campaign to seek regional tourism cooperation. Changchun and the major cities of the Russian Far East have jointly organized the Tourism Exchange Promotion Conference and signed the tourism cooperation agreement, and carried out the youth exchange activities of "Learning Chinese Summer Camp" and "Sino-Russia Friendship Tour" among the Russian primary and middle school students.

Exploring the common cultural memory is a basic project for humanistic cooperation. In 2013, Jilin Province established "Northeast Asia International Language and Cultural Research Base" to strengthen the study in humanistic field of language, folklore and diet and so on of Northeast Asia, including Russia The base, jointly built by Jilin University and Tumen River International Cooperation Society and its members include seven universities ${ }^{4}$ in the three provinces of the northeast, conducts an in-depth study of the regional culture of Northeast Asia together.

In September 2014, Jilin Provincial Press Office held "Seminar on Media Exchanges between Jilin Province and the Russian Far East". Media representatives from more than 10 medias, including "Russian Newspaper", Khabarovsk "Businessman", Vladivostok "Golden Horn", Maritime Kray Public Television Station, and Far East "Oriental Media", have made in-depth exchanges with the representatives of major newspapers, radio station and TV station of Jilin Province and discussed on specific cooperation projections.

In Northeast Asia Investment and Trade Expo held in Jilin in 2014, several influential international conference activities, such as the Northeastern Asian Culture and Art Week, the Northeast Asia Think Tank Forum, the Cultural Project Promotion Forum and the Northeast Asia Youth Entrepreneurs Development Forum, have been added. It also clearly defined the Expo as "an important channel to promote the cultural exchanges and cooperation between the countries of Northeast Asia". Thus, it can be seen that Jilin has further deepened the form of cultural exchanges and cooperation with Russia. [5]

New progress has been made in exchanges and cooperation between the two sides in colleges and universities and the accumulation of talents major in Russia. In the field of jointly running schools, a number of colleges and universities have made new developments in the cooperation with Russia in undergraduate education ${ }^{5}$, such as Jilin University, Northeast Normal University, Changchun University, Jilin Institute of Construction and so on. In regard to the gathering of talents major in Russia, Jilin province launched a project of "a hundred young scholars to participate in the research support project of Northeast Asia" in 2014, so as to provide intellectual resources for the implementation of "Changchun-Jilin-Tumen

The seven universities are Jilin University, Heilongjiang University.

The latest progress in the cooperation of universities of Jilin and Russia in 2014 is the undergraduate education project in the subjects of architecture and engineering management, etc. between Jilin Architecture and Civil Engineering Institute and the Russian Pacific National University, and the jointly organizing of education in mechanical engineering and automation between Changchun University and Russia's Ustinov Baltic State University of Technology. 
Development Strategy" and the cultural exchanges and cooperation with Russia.

In addition, many university presidents in Jilin province actively participated in the "Sino-Russia University President's Forum"; Scholars in various fields have actively participated in the "Rostrum of Chinese and Russian Young Scholars"; Northeast Normal University established a Russian youth Chinese Wushu study camp; Changchun University held "Photography Exhibition of Russian Prime Minister Medvedev and Teachers and Students of Changchun University"; Yanji launched the first "Sino-Russia Yanji Youth Swimming Friendly Competition" and other activities, to showing "Wonderful Jilin" to the Far East in many fields, which further improved the popularity of Jilin in the Far East. These activities have effectively promoted people's understanding towards the culture and national psychology of each other, truly enhanced the daily communication between the two peoples, further deepened the mutual friendship and understanding, and made great progress in the field of humanistic exchanges and cooperation between the two sides, reflected a good development posture.

\section{B. Major Problems in Humanistic Exchanges and Cooperation Between Jilin Province and the Russian Far East}

At present, the humanistic exchanges and cooperation between Jilin and the Russian Far East are mainly carried out in the aspects of education, science and technology, culture, tourism, sports and media. Although some achievements have been achieved, the communication and cooperation are still in the initial stage. Therefore, the depth and breadth of humanistic exchanges and cooperation between the two sides still have much room for improvement. The main problems lie in the following aspects:

First, there is no long-term mechanism for humanistic exchanges and cooperation between the two sides. There is no complete communication mechanism between the two governments, nor regular exchange visits and meetings. In the humanistic exchanges and cooperation between the two sides, without the guarantee of long-term cooperative mechanism, the executive organs lack the main body spirit that the goal and overall arrangement of cooperation between the two governments are difficult to made. Since there is no normalized operation, it is difficult to make in-depth exchanges and cooperation in various fields such as academic circle, literature and art circle and education circle. Second, the characteristic cultural brand of Jilin Province is not prominent enough. In the process of culture "going out", the local cultural products which represent the national standard and reflect the characteristics of Jilin are relatively scarce. Third, the theme of humanistic exchange and cooperation needs to be expanded and people's cross cultural communication needs to be improved. Fourth, there is a shortage of senior Russian talents. At presents, the talents that are professional in academic knowledge and proficient in Russian are terribly scarce. The lack of training of high-end applied talents affects the deepening of talent exchanges and cooperation between the two sides. Fifth, the reality that "senior people are enthusiastic while the young people are cold" in communication with
Russia still exist. Those senior people who were influenced by the Soviet Union were more enthusiastic about exchanges with Russia, and the younger generation did not know each other enough. Therefore, the humanistic exchanges and cooperation need to be improved both in breadth and depth.

\section{OBJECTIVE OF HUMANISTIC EXCHANGES AND COOPERATION BETWEEN JILIN PROVINCE AND THE RUSSIAN FAR EAST}

According to the Changchun-Jilin-Tumen Development Plan and the Development Plan of the Russian Far East, Jilin province should formulate the overall plan of the strategic upgrading of the humanistic communication and cooperation with the Russian Far East for the present and the future.

In general, the overall objective of humanistic exchanges and cooperation between Jilin Province and the Russian Far East is to carry out the humanistic exchanges and cooperation with the Russian Far East in an all directional, multilevel and multiform mode that based on Chinese traditional culture, emphasized on the promotion of Jilin culture, supported by the governments of the two sides, conducted by the official and public institutes, targeted at the youth of the Russian Far East and linked by the bilateral academic cultural exchanges.

In order to ensure the scientific nature of the objective and trend of the mutual cooperative development, five-year shortterm objective, ten-year middle-term objective and 15-year long-term objective should be made respectively, gradually expand humanistic influence toward Russia.

\section{COUNTERMEASURES OF STRENGTHENING HUMANISTIC COOPERATION BETWEEN JILIN PROVINCE AND THE RUSSIAN FAR EAST}

\section{A. Establishing a Long-term Mechanism for Humanistic Cooperation}

In order to make the cooperation between the two sides more profound and effective, we need to establish a long-term mechanism for cooperation. Intergovernmental communication and meetings have a guiding effect on exchanges and cooperation between the two sides. The government should strengthen communication and provide guidance to the exchanges and cooperation in various fields of humanity. The two sides can establish regular intergovernmental visits mechanism, and sign regular scholars exchange mechanism and exchange cooperation mechanisms in other fields, so as to establish a stable cooperative relationship. The long-term mechanism can serve to promote the exchanges and cooperation in various fields of government and the public and thus form a cooperation mode that lead by the government and participated by the public.

\section{B. Strengthening Publicity and Enhancing the Cooperation Initiative}

Through all kinds of publicity activities, the society and the public can have a clear understanding of the necessity and feasibility of humanistic cooperation, form a good cooperative atmosphere, and also reflect the achievements of win-win 
cooperation through joint participation, common sharing, common development and common vision. In particular, it is necessary to urge all kinds of cultural departments to actively communicate with Russia, establish communication channels, create a direct communication platform for both the business circles, cultural circles, science and technology circles and academic circles by organizing various forms of conferences, exchanges and academic seminars, and carry out humanistic cooperation in the various fields.

\section{Strengthening Scientific Research Cooperation and Actively Expanding Personnel Exchanges with Russia}

Cooperation in scientific research should be strengthened. Scientific research cooperation is a development trend for future cooperation with Russia, and also a result of the development of personnel exchanges to connotative development. Jilin Province is advanced in scientific and technological industry. Chinese Academy of Science Changchun Branch, Changchun Institute of Applied Chemistry and Jilin Academy of Social Sciences have strong scientific power and remarkable research achievements, occupied a certain position in the whole country. A number of key national colleges and universities such as Jilin University and Northeast Normal University take the leading role in the country in the fields of optics, biotechnology, automobile manufacturing, traditional Chinese medicine and higher education. There are research centers ${ }^{6}$ in all states in the Far East and each department has a research institutions ${ }^{7}$. Research institutes and colleges of higher learning in our province can establish cooperative cooperation relations with research institutes in the Far East, set up project teams and hold seminars. While developing scientific research cooperation, we should actively expand external personnel exchanges. Personnel exchanges include exchanges of students, scholars, official team and folk communications, etc. We can set up the special funds for regional personnel exchanges and constantly increase the number of students sent to the counterpart. In addition, we can also promote the establishment of friendship organizations at all levels, fields and industries, and strengthen the organizing and coordination of cultural exchanges and cooperation with Russia.

\section{Developing Education Cooperation and Promoting Connotative Development of Communication and Cooperation}

In terms of educational cooperation, we should expand the scope of cooperation, enhance the influence and competitiveness of education in Jilin, and carry out educational cooperation in multilevel and wide range. Educational cooperation can cultivate high-level talents with cross-cultural

6 The Far East scientific research center includes Maritime Kray Science Center, Kamchatka Science Center, Sakhalin Science Center and other institutions.

The main research institutions in the Far East include: Far East Institute of Architectural Design for Industrial Enterprise and Institute of Epidemiology and Microbiology established in Haishenwai; Far East Institute of Forestry and Agricultural Science established in Khabarovsk; Russian Soybean Research Institute and Far East Institute of Veterinary Medicine established in Blagoveshchensk; Institute of Gold and Rare Metals established in Magadan Oblast, etc. communication skills and provide valuable human resources and intellectual support for further deepening Sino-Russia relations. Jilin and the Far East have many colleges and universities, ${ }^{8}$ which laid a sound foundation for educational cooperation. Colleges and universities of the two sides can cooperate in operation. By using modern concepts and educational means, they can maximize their respective advantages and cooperate in running schools. In recent years, Jilin Institute of Construction Technology and Changchun University have held some cooperative education projects with Russia. ${ }^{9}$ In addition, colleges and universities from both parts can establish the joint research center, strengthen the strategic research on Sino-Russia relations and the empirical research on the social problems of the two countries, and realize the operational mechanism of scientific research cooperation centered on task pulling or the scientific research operation mechanism, and based on the organization and management system that in charge by the experts, so as to better spread the values and excellent culture of the two countries, serving for the national strategy and Jilin's cooperation with Russia, providing the solid theoretical basis and detailed data for SinoRussia humanistic exchanges and cooperation and providing intellectual guarantee and paradigm guidance for cultural identity and strategic cooperation between the two countries.

\section{E. Strengthening the Training of Russian Talents}

We should pay attention to the accumulation, excavation and integration of Russian talent resources, and strengthen the training of compound Russian professionals. Universities in Jilin Province that opened Russian subject can draw the valuable experience from Heilongjiang University in running a school with Russia. ${ }^{10}$ They can also employ senior experts and scholars who still have "Russian complex" in the province to take part in the cultivation of compound talents major in Russian in Jilin Province. The government can encourage and guide the public to learn Russian actively, set up incentive mechanisms and special funds, and reward outstanding Russian talents. At the same time, increase the number of students studying in Russia and train more talents major in Russian.

\footnotetext{
8 There are 29 colleges and universities in the Russian Far East, including Far Eastern Federal University, Far Eastern Polytechnic University, Amur State University, Far Eastern State Technical University, and Vladivostok State University of Economics and Service, etc.

Technical engineering, agricultural science, education, medicine and ecology in Far Eastern colleges and universities are the majors with professional characteristics. Universities in the province can cooperate with them in these academic fields.

10 The experience of Heilongjiang University in running school with Russia: first, deepening the reform of personnel training mode and expanding the training of "Russian + direction" compound and "professional + Russian" dual degree talents; second, emphasize the training of professional talents targeted Russia in various subjects. The university has set up "Zero-start" experimental class among the freshmen major in science and technology, cultivating talents that not only have the professional knowledge of engineering science, but also know well of Russian and Russian national conditions, so as to serve the large enterprises cooperate with Russia. In the subject of literature, history and philosophy, Russian culture, national conditions, history and other courses are set up to train talents that are professional in Russian conditions.
} 


\section{F. Developing Cultural Industry Actively}

Chairman Xin Jinping put forward that the humanistic exchanges between China and Russia should be developed from general friendly exchanges to the common development of cultural industries and so on. The two sides should take cultural industry as the pillar industry of the national strategy, and the common development of the cultural industry will be beneficial to the complementary of the advantages and resources, and thus improve the cultural competitiveness and attraction of the two countries.[6] At present, the humanistic cooperation of the two sides should take cultural industry cooperation as the push and combine the cooperation of various fields in the province with the development of cultural industry, and thus build a new mode of cultural industry oriented humanistic cooperation. On the basis of existing exchanges and cooperation, characteristic cultural industry should be emphasized and explored to be the shinning spot different from other provinces, making it the new brand of the province in the humanistic cooperation with Russia. On the choice of specific cultural industries, it is suggested to strengthen cultural industry cooperation in the fields of film, Chinese medicine and tourism. The joint development of the cultural industry also reflects the high degree of agreement between "Chinese dream" and "Russian dream".

In terms of film culture cooperation, the two sides can regularly organize film exchange week, film festival and other activities, as well as jointly shoot outstanding film and television works. Changchun film studio is the cradle of Chinese films, which has accumulated a lot of tangible assets and intangible resources of new China movies. In recent years, the film and TV industry in Jilin province has strong momentum of development, and the film and television works that reflect the social life of the two peoples can be shooting jointly. In terms of traditional Chinese medicine culture, Chinese medicine industry has become the pillar industry of Jilin. In Russia, Chinese medicine has been recognized by the public. The Russian government plans to include traditional Chinese medicine in the "Healthy Russia" project. The two sides can expand exchanges and cooperation in the field of traditional Chinese medicine through exchanges of personnel and projects between medical institutions and hospitals. It includes various forms of cooperation like sending students to the other part, cooperation in running schools, creating a "forum on Chinese and Russian traditional Chinese medicine" and cooperative research projects, strengthening exchanges and cooperation between the two sides in the field of Chinese medicine. Jilin is rich in tourism resources ${ }^{11}$. Through various promotion activities, we can make the people in Far East area know that Jilin is a tourist resort where has warm and green spring, cool summer, fruitful autumn and beautiful winter. Tourism cooperation between the two sides has a broad prospect through the exploration of Jilin tourism resources and development of cultural tourism industry.
In addition, the cooperation body should also be expanded. Due to the constraints of historical conditions, exchanges and cooperation in the past have formed a thinking set of "form first, without effect". At present, the two sides should integrate the activities of human exchanges and cooperation with the increasingly improved economic cooperation structure of the two countries, extend the exchanges and cooperation into the public as soon as possible, further expand the theme of cooperation, and carry out multilevel activities that can deeply impress the public. For example, the two sides can hold a series of activities like Chinese and Russian Song Contest, art festival between friendly cities, invite students to participate in the "local summer camp", art festival and academic forum among university students, letter writing activity among the young students and various exhibition activities, and thus further promote exchanges and communication between young people. In addition, we can also hold all kinds of sports competitions, establish bibliographic database between the two libraries and regularly organize Chinese and Russian cultural book exhibitions and other activities.

\section{CONCLUSION}

To sum up, giving full play to the functions of the government is the premise of the humanistic exchanges and cooperation between the two sides, the active participation of the public is the guide, and the establishment of a cooperative normal mechanism is the key and guarantee. Therefore, on the basis of the existing cooperation achievements, the two governments should strive to establish a modern and international humanistic exchange and cooperation mode adhere to the principle of subjectivity, pluralism, guidance and developing by gathering the power of the society and the wisdom of the public.

\section{REFERENCES}

[1] Huang Shouqi, Zhang Shanwen, Zhou Yi translate [M]. Shanghai: Shanghai Classics Publishing House, 2007.

[2] Albert W. Levi. The Humanities Today [M]. Bloomington: Indiana University Press, 1970. Albert W. Levi. The Humanities Today[M]. Bloomington: Indiana University Press, 1970.

[3] Wei Jingjing, Cultural Cooperation between China and Central Asian Countries under the Framework of the Shanghai Cooperation Organization, Theory Front, 2013 (6).

[4] Liu Yandong. Deepening Cooperation in Higher Education and Opening Up a New Situation of Humanistic Exchange in Asia [J]. Journal of World Education, 2010, (12).

[5] Humanistic Exchange is the Connector --- Interpretation on China Northeast Asia Investment and Trade Expo by International Experts. [EB/OL].http://www.chinajilin.com.cn/jlnews/content/201308/26/content_2979403.htm.

Improving the Soft Power: New Task in Sino-Russia Humanistic Cooperation [N]. Guangming Daily, 2014-11-28.
11 The major scenic spots in Jilin Province include Changbai

Mountain Tianchi, Songhua Lake, Changchun Manchurian palace, Jingyuetan Pool, Changchun Movie Wonderland, Jilin Beishan, Beidahu, Nongan Stupa, Jingyu Ceretery in Tonghua, etc. 